\title{
Controversy on iron needs, intake levels, deficiency stigmata and benefits from iron supplementation
}

\author{
AleXander R. P. WAlker \\ D.SC. \\ C.S.I.R. Human Biochemistry Research Unit, \\ South African Institute for Medical Research, \\ Johannesburg, South Africa
}

\begin{abstract}
Summary
At present there is considerable controversy over many aspects of iron nutrition, including: (1) iron needs and intake levels; (2) the bearing of iron intake on haematological levels; (3) iron deficiency anaemia and deficiency stigmata; and (4) iron therapy, prophylaxis, and the haematological and clinical benefits accruing.

Differences of opinion prevail because of inadequacies of knowledge of the level of haemoglobin (or other parameter of iron status) below which unequivocal signs and symptoms of illhealth become manifest in the major proportion of those affected. Difficulties arise equally from lack of knowledge of the level of haemoglobin above which no clinical benefit, short-term or long-term, can be detected from iron supplementation.

Clarification of the situation can be obtained only by carrying out the same meticulous and timeconsuming procedures that have been used in respect of requirements and deficiency stigmata of other nutrients. Comprehensive iron depletion studies, real and simulated, and repletion studies, including the use of placebos, will be required.
\end{abstract}

Epidemiological investigations bearing on haematological status and morbidity will also need to be undertaken, and include groups of subjects in both Western, and developing countries.

\section{Introduction}

Within recent years there have been many symposia, reviews and other contributions on iron nutrition. Nevertheless, considerable differences of opinion remain on iron requirements and intake levels, interpretation of haematological values, the precise degree of ill-health due to anaemia, the rationale of treatment, and the nature of the benefits resulting. Evidence of these uncertainties was apparent at a Symposium held in London in 1966 by the Royal Society of Medicine. Kilpatrick (1966), in a paper on 'The Presymptomatic Diagnosis of Anaemia', asked questions such as:
'Do arbitrary levels of haemoglobin below which anaemia may be said to be present still serve a useful function?' 'Are the present conventional levels the correct ones?' The extent of the controversy on some of the aspects mentioned will now be described.

\section{Iron needs and intake levels}

Various dietary-standards bodies, which reflect consensus opinions, have compiled recommended intakes of nutrients. In the case of iron suggested intakes until recently have ranged from 10 to $15 \mathrm{mg}$ per diem during growth and for men and nonpregnant women, and 13 to $20 \mathrm{mg}$ during pregnancy (WHO Expert Committee Report, 1965). Recommended allowances are much higher than minimum physiological requirements. It has, therefore, been startling to note that the Council on Foods and Nutrition (1968) of the American Medical Association maintains that daily iron requirements are higher than the ranges given; the amount for pregnant women, for example, is given as $20-48 \mathrm{mg}$. It was asserted that: 'This amount ... cannot be derived from the diet and should be met by iron supplementation in the latter half of pregnancy.' The foregoing is endorsed in the new publication on 'Nutritional Anaemias' (WHO Report of a Scientific Group, 1968). In strong contrast, however, in Britain, the daily intake of iron for pregnant women now recommended by the Department of Health and Social Security (1969) is $15 \mathrm{mg}$. Examples of opinions of individuals are as follows: In speculating on optimal iron balance, Finch (1965) has stated that in respect of iron intake, all everyday diets are inadequate. He suggested "that an "available" iron intake of twice that now being ingested by the world population might be highly desirable ... this might be translated into some 10 or $15 \mathrm{mg}$ of iron salts added to food'. This depressing view is alarming. Witts (1964) has emphasized that 'some physiologists are perturbed that we should need to give iron so frequently.... It is a puzzle to me 
that $20-25$ per cent of women in the reproductive epoch in Great Britain should be anaemic, despite the rise in the standard of living'. He concluded, presumably ironically, "it seems as if Nature has managed badly'. Moore (1964), however, is content with a lower target than Finch (1965); he considers that ' $15-18 \mathrm{mg}$ of food iron should be sufficient for all normal adults, with the possible exception of women during pregnancy. In pregnancy the recommended dietary allowances might better be $18-21 \mathrm{mg}$. These values ... are attainable in many countries'. At the lower extreme of intake, Hawkins (1964) has summarized several recent studies which led to the conclusion that 'a daily intake of about $5 \mathrm{mg}$ of iron is the level below which negative balance is likely to occur in adults, but that intakes below this are adequate for children less than 10 years of age'.

In respect of actual intakes, Witts (1964) is not nearly as happy as Moore (1964) about the level of iron attainable from modern diets. Callender (1964), too, thinks that diets in reality may contain less iron than the amount calculated from food tables: she referred to a diet made up in her hospital (Radcliffe Infirmary, Oxford), considered to be adequate, but which contained as little as $6-7 \mathrm{mg}$ iron per diem. In Britain, national daily intakes of iron have been stated to be approximately 11-18 mg per capita (Domestic Food Consumption and Expenditure, 1961). In a recent investigation by Davis, Jacobs \& Rivlin (1967), it was estimated that average daily intakes for the groups of men and women studied were 17.5 and $14.1 \mathrm{mg}$ iron, respectively. During pregnancy and lactation, knowledge of levels of intakes of nutrients are said to be 'extremely scanty; particularly is this true of data from developing countries' (WHO Expert Committee Report, 1965).

Briefly then, firstly, there is a gross difference of opinion over the amount of iron deemed necessary per diem, especially for pregnant women. This obviously makes for confusion over the labelling of iron intakes as deficient or adequate. Secondly, there is controversy as to the actual iron intake of western populations; still more so must this apply to primitive or emerging populations. In recognition, the Council on Foods and Nutrition (1968) stated that 'Further studies are urgently needed... to clarify further the availability of food iron and the actual dietary iron intake of the population'.

\section{Iron intake and haematological values}

Many laboratory tests have been used, singly or together, as indices of iron status, namely, haemoglobin level, mean corpuscular haemoglobin concentration, serum iron level, percentage saturation of iron binding capacity, appearance of blood smear, concentration of iron enzymes in tissues, and the presence of iron in bone marrow. Apart from situations where iron intakes are very low, or where there are significant losses of iron from blood loss or destruction, our knowledge of the bearing of the level of iron intake on the parameters mentioned is unsatisfactory. Thus, Davis et al. (1967), in the investigation previously referred to, found that in both sexes there was a complete lack of correlation between the dietary iron intake and the haematological findings, in respect of haemoglobin level, mean corpuscular haemoglobin concentration, serum iron and serum iron-binding capacity, and transferrin saturation.

\section{Iron deficiency anaemia and deficiency stigmata}

The laboratory and clinical asyects will be discussed together. For the purpose of this paper, only the index of haemoglobin level will be considered.

The crux of the problem, as Hawkins (1964) has pointed out, concerns 'what to accept as an adequate, satisfactory, or normal haemoglobin concentration'. What is the haemoglobin level below which iron deficiency anaemia may be said to be present? Various levels have been employed. For men, values of 12-14 $\mathrm{g}$ haemoglobin/100 ml have been used; for non-pregnant women cut-off values of $12 \mathrm{~g} / 100 \mathrm{ml}$ has been adopted; and foro pregnant women 10-11 g/100 ml (WHO Expert Committee Report, 1959; Council on Foods and Nutrition, 1968). Reasons rarely are given for the critical levels employed, thereby rendering them arbitrary. Kilpatrick (1966) has stated: 'For many years conventional and arbitrary levels of anaemia have been used; in general, anaemia has been defined in men as a haemoglobin level of $12.5 \mathrm{~g}$ per cent or less, and $12.0 \mathrm{~g}$ per cent or less in women. These are probably convenient levels, but one could argue about their arbitrariness and it is perhaps rather unrealistic that men have to be proportionately more anaemic than women before they are defined as having anaemia.' It is interesting to note that in a survey in a London practice by Fry (1961), the same critical level, namely, $80 \%$ or $11.85 \mathrm{~g} / 100 \mathrm{ml}$, was used for both sexes; this employment of a common yardstick evoked neither challenge nor comment. Is there specific evidence that clinical signs and symptoms of iron deficiency begin to occur at higher levels in men than in women?

To the nutrition worker-from whose point of view this paper is written-a crucial question is, in persons with haemoglobin levels below those given, and who are accordingly classified as anaemic, in what way do they suffer? More specifically, below what haemoglobin level do clinical signs and symp- 
toms occur, either invariably, or in a large proportion of the affected? Conversely, above what haemoglobin level (or other parameter of iron status) does supplementary iron no longer confer clinically detectable benefit? Unfortunately, adequate answers to neither of these questions are forthcoming, particularly the latter. In a study on the symptoms of iron deficiency in anaemia, Wood \& Elwood (1966) concluded: 'Limited evidence was found to suggest that in severe anaemia, symptoms and haemoglobin level may be associated. However, for mild anaemia there is no association, or other common ailments effectively mask any relationship which may exist.' Elwood (1968) maintains that 'Any single diagnostic criterion of anaemia in terms of a level of circulating haemoglobin concentration is unreasonable, unless it is shown that levels below this are significantly often correlated with ill-health'.

Further examples underlining the lack of information are as follows. Kilpatrick (1966) has stated: 'The symptoms usually attributed to anaemia are dyspnoea, fatigue, palpitation, lack of concentration, etc., but these are also the symptoms of many other disorders and in particular of psychoneuroses. Because they are rather non-specific it is possible that the association of symptoms and anaemia is fortuitous, as both anaemia and the psychoneuroses are common in the community at large.' In an Editorial (1961) on 'Prevalence of Anaemia' in the British Medical Journal, it was stated: 'If anaemia is so prevalent, what are the clinical signs and symptoms that suggest to the practitioner that investigation will be worth-while? The classical symptoms are increasing and undue fatigue after tasks normally undertaken without discomfort, dyspnoea and palpitation after moderate exertion, and sometimes swelling of the ankles, especially in the evenings; soreness of the tongue and flatulent indigestion may occur. On examination the conjunctivae will be pale, the tongue may be smooth, the nails spoon-shaped, and the pulse rapid.' Notwithstanding, it was admitted that in practice, only a minority of patients show clear signs and symptoms of anaemia, and it is remarkable how low the haemoglobin level can fall before the patient seeks advice'. Beutler (1964) has stressed that there is a poor relationship between anaemia severity and the symptoms displayed by iron-deficient patients. Dreyfus (1964) asked 'How are we to explain the fact that many of the signs and symptoms allegedly due to depletion of tissue iron are quite unusual in severe iron-deficiency anaemia, even of long duration?' Moreover, Pollycove (1964) has stated: 'Severe cases of iron deficiency occur frequently in various parts of the world where heavy labour is performed for many years by anaemic individuals at haemoglobin levels of 4-6 $\mathrm{g}$ per 100 ml.' Foy \& Kondi (1957) frequently have drawn attention to numerous African patients in the tropics and semi-tropics who have haemoglobin levels of $2-4 \mathrm{~g} / 100 \mathrm{ml}$, and yet who maintain that they feel well and are able to carry out their everyday work. Surely, it should be possible to demonstrate in what respects these unquestionably anaemic people suffer, or are at a health disadvantage, compared with their associates who have haemoglobin levels: (i) within the 'normal range', and (ii) which are intermediate.

\section{Anaemia in pregnancy}

The state of knowledge in relation to the significance of anaemia in pregnancy is especially disconcerting. The interpretation of the haemodynamic and other changes involved has occasioned much discussion (Baird \& Hytten, 1959). Plasma volume increases by about $50 \%$, but red cell mass by about $20 \%$. Thus, despite an absolute increase in total circulating haemoglobin, haemoglobin and haematocrit levels usually fall. The decrease is of the order of $10-15 \%$. The usual fall in blood values is regarded by most haematologists as specific evidence of iron deficiency, simply since the fall can be largely abolished by supplements of iron compounds. The WHO Expert Committee Report (1959) on 'Iron Deficiency Anaemia' suggested that anaemia can be considered to exist in the pregnant female when the haemoglobin concentration is below $10 \mathrm{~g} /$ $100 \mathrm{ml}$. The WHO Expert Committee Report (1965) on 'Nutrition in Pregnancy and Lactation' agreed that 'this level may be accepted as a general indicator of the lower limit of physiological adjustment during pregnancy'. Yet, in neither of these Reports, nor in other contributions, is there satisfactory information on the low levels of haemoglobin concentration in pregnancy which are consistent with prejudice to well-being, whether assessed objectively or subjectively, whether from shortterm or long-term observations. In a review on the subject, Hytten \& Duncan (1956) commented: 'It is significant that in pregnancy, apparently severe anaemia may be symptomless. For example, a third of the women found by Lillie et al. (1954) to have less than $10 \mathrm{~g} / 100 \mathrm{ml}$ had no symptoms, and symptoms were not always found until the haemoglobin concentrations were as low as $6 \mathrm{~g}$ / $100 \mathrm{ml}$.' Much the same observations were made earlier by Magee \& Milligan (1951). The WHO Expert Committee Report (1965) emphasized that "clinical standards considered "normal" for the non-pregnant woman cannot be used as standards for pregnant women'. Failure to recognize this has led to many inaccurate appraisals of nutritional status, false claims concerning anaemia and misleading estimates of needs of certain nutrients. 
'There is an immediate need for the establishment of biochemical standards in relation to healthy, pregnant and lactating women, for use in appraising nutritional status during the reproductive cycle.' Other authorities, too, have urged the need for unemotional thinking on the subject. For example, Crosby (1966) has ridiculed 'the hyperthermic attitudes which generally prevail concerning the iron requirements in pregnancy... The suspicion or even the diagnosis of iron deficiency in a pregnant woman is no indication for overblown attitudes and heroic recommendations'.

\section{Anaemia in underdeveloped countries}

Additional uncertainties regarding the occurrence and significance of iron deficiency anaemia have been reported from underdeveloped countries. Thus, Trowell (1960), writing from Africa, stated: 'one is surprised how much anaemia is present before the patient seeks treatment ... The stigmata of iron deficiency anaemia, as encountered in other races, are not common in Africans. Definite koilonychia is uncommon, so is soreness of the tongue; the Plummer-Vinson syndrome is rare. The various gastro-intestinal disabilities of the Europeans are less commonly reported, and achlorhydria was present in only a small minority of cases examined at Mulago Hospital (Uganda).' To what extent is Trowell's view in harmony with other reports? In the WHO Expert Committee Report (1959), it was maintained that 'Anaemia constitutes a public health problem of considerable importance in the underdeveloped and tropical areas of the world. In some countries, for example, India and Mauritius, it seems probable that the high rates of maternal mortality are influenced by the prevalence of anaemia.' Nevertheless, the Committee admitted, 'Although there is ample circumstantial evidence indicating the close association of anaemia with high maternal and infant mortality, there is scanty information as to the precise extent to which anaemia contributes to mortality, morbidity, and impairment of working capacity'. In a summary in the Lancet of a Conference on 'Anaemia in Africa' (1962a) held in Kampala, Uganda, it was stated: 'The contributions emphasized the immense importance of anaemia as a cause of morbidity and mortality in Africa.' Examination of the papers read does not bear out this extravagant opinion ('Anaemia in Africa' Conference, 1962b).

It will be appreciated that while there are inadequacies of knowledge in respect of iron deficiency linked with anaemia, still more so are there uncertainties in respect of iron deficiency in the absence of anaemia (Beutler, 1964; Cochrane \& Elwood, 1968; Elwood et al., 1969).
Iron therapy, prophylaxis and benefits resulting

It must be emphasized that there is, of course, no dispute whatever over the need of iron when haematological values are uncontestably low. The problem at issue concerns persons with intermediate values below the 'normal range', and also that huge proportion of populations with haematological values within the 'normal range' but which can be increased by means of additional iron.

Regarding benefits from iron supplementation: in infants and young children, the early studies of Mackay (1931), and more recently of Undriz (1964), and of Andelman \& Sered (1966), have indicated that iron supplementation certainly can elevate haemoglobin levels in a very large proportion of subjects, with or without anaemia, and apparently can ameliorate morbidity. Mitchell (1966), however, has cautioned that because of the haematological responses evoked, 'it should not be assumed ... that most infants are anaemic'. Unequivocal proof is urgently required, both of the reduced morbidity in infants claimed to arise from the addition of iron, and also of the benefits to infants and children following elevations in haematological levels, especially in those who are non-anaemic.

In respect of pregnant women, the WHO Expert Committee Report (1959) stated: 'Pregnant women will derive great benefit from additional iron in the form of a three-grain $(180 \mathrm{mg})$ tablet of ferrous sulfate containing $63 \mathrm{mg}$ of elemental iron, or the equivalent of another iron compound, once daily throughout pregnancy and the first six months of lactation. Should the woman's haemoglobin be below $10 \mathrm{~g} / 100 \mathrm{ml}$ of blood, additional iron should be prescribed.' The character of the 'great benefit' likely to be obtained was not enlarged upon. In the WHO Expert Committee Report (1965), it was stated: 'Superficially, the physiological change resembles the manifestations of iron deficiency anaemia and can often be reduced by giving iron in therapeutic quantities. In many ante-natal clinics iron is therefore prescribed routinely. There is no sound clinical evidence that in a generally healthy population this benefits the normal mother or foetus. Sturgeon (1959) has shown in California that despite considerable "improvement" as judged by haematological criteria, large doses of iron given during pregnancy conferred no apparent benefits. His treated and untreated mothers became haematologically indistinguishable six months after birth, and at no time was there evidence of "improvement" in the babies.' The Report continued: 'The Committee feels that the indiscriminate issue of iron preparations as a routine to all pregnant women in situations where there is no obvious indication for them is to be deplored. It is not merely wasteful; it also impedes research upon the problem and a 
more rational approach to the prophylaxis and treatment of anaemia.' The Committee insisted on the need for research to assess 'the degree of benefit which can be expected among pregnant and lactating women, as well as in the general population from such a measure' (iron supplementation). Paintin, Thomson \& Hytten (1966), in their investigation on 'Iron and Haemoglobin Level in Pregnancy' reported that there was no correlation between the answers to the questions, 'How do you feel?' 'Are you breathless?' and haemoglobin concentration, total red cell volume or serum iron concentration, in controls and in groups of subjects treated with 12 and $100 \mathrm{mg}$ iron (as aminoates) per diem. Thomson, Hytten \& Paintin (1967) have recently stated: 'It would be a pity if dogmatic assertions about the prevalence and nature of anaemia in pregnancy led to a situation where it became unethical to withhold iron supplements, even in the absence of definite ill health.' In view of the gross uncertainties and of the plethora of speculations prevailing, can it be seriously maintained that the diets of all pregnant women, from those in the most prosperous societies downwards, are inadequate in regard of iron concentration? Further, since $80 \%$ of western pregnant women may be expected to respond to iron therapy (Kerr \& Davidson, 1958), can it be sustained that this proportion will suffer detectably if supplemental iron is withheld?

In pregnancy, it is well known, of course, that mean haematological values are higher in groups who receive supplementary iron compared with those who do not (Crosby, 1966). Accordingly, there are some who argue that since the fall during pregnancy can be abolished or at least reduced by iron supplementation, why not, as a public health measure, consider prophylaxis for all pregnant women, whether anaemic or not? It may be reasoned that as preventive procedures we are subjected to mass immunization against infections. We are supplied by local authorities with pure water and pasteurized milk, and our diets, variously, are supplemented with B vitamins and calcium salts. There is fluoridation of water to protect against caries, iodized salt to safeguard against goitre, etc. Why may not iron prophylaxis in pregnancy-whether the need be present in $5 \%$ or $50 \%$ of women-be regarded in exactly the same light? After all, additional iron of the magnitude usually given, does no harm. There is much that is plausible in this point of view. The relevant authorities in U.S.A. and Britain would be just as hard pressed to justify the addition of $B$ vitamins and calcium salts, respectively, to the staple bread meal, as would be the protagonists who recommend iron prophylaxis for all pregnant women. Many, however, feel increasingly that the suggestion of mass prophylaxis is too facile. This reaction is apparent in the change of view-point in the 1965 compared with the 1959 WHO Expert Committee Reports, also in an earlier Leading Article (1958) in the Lancet on 'Anaemia in Pregnancy', compared with the statement of the Editor in 1963 ('We have certainly changed our views'). In recoiling from the 'mass handing out of iron pills' (Leading Article, 1963), a number of authorities have advocated screening procedures. But their nation-wide feasibility, even in Britain, let alone in primitive or in developing countries, has been questioned (Kilpatrick, 1966). This worker has suggested an alternative and certainly more fundamental approach: 'Before recommending countrywide facilities for haemoglobin testing, one should perhaps pause a little to ask whether "screening" in general is not liable to produce a certain amount of smugness because one is "doing something for the community", and one should also ask whether this is not a little too easy to do, compared with the difficult, boring, prolonged, all-too-often not statistically significant, though certainly more rewarding, task of carrying out properly randomized controlled clinical trials.' Evidence of benefit from such trials, however, excluding that demonstrable in cases of severe anaemia, may not be readily forthcoming. Elwood (1968) reached the conclusion that 'Iron deficiency anaemia has largely ceased to be an important subject for clinical research. The initiative has passed largely to the epidemiologist, as only in community studies can an unbiased evaluation of haemoglobin level as an index of health be made, and only in community studies can the long-term effects of prophylactic measures adopted at the national level be assessed.' Even in underprivileged populations, benefits from supplementation are not always readily demonstrable. In considering nutritional supplementation generally, Walker (1963) regretted the scarcity of evidence of benefit arising from the supplementation of the diets of pregnant and lactating women, indicating that this particular lack of knowledge was 'especially humbling'. Recognition of this is evident in the WHO Expert Committee Report (1965) in which it was stated: 'The Committee wishes to emphasize that the areas of ignorance relating to nutrition in pregnancy and lactation are extremely large, and it is impossible as a rule to state didactically that this or that particular form of dietary change will produce a specific clinical benefit.'

In scarcely any of the aspects discussed has the WHO Scientific Group (1968) on 'Nutritional Anaemias' displayed appreciation of the problems at issue.

Although, in this paper, uncertainties of knowledge have been discussed primarily with reference to the significance of haemoglobin level, it is considered 
that uncertainties prevail equally if not more so in respect of the other indices of iron status mentioned.

\section{Discussion}

It is -ironical that at the present time attempts to maintain haemoglobin concentrations at their highest level are lauded, whereas in the not too distant past, phlebotomy in the sick was practised with alacrity on all possible occasions. As late as 1923 , Osler \& Macrae felt it necessary to assert that "The reproach of Van Helmont that "a bloody Moloch presides in the chairs of medicine" cannot be brought against this generation of physicians'.

The crux of the problem, generally, is epitomized by the following quotations. 'Is a given level of haemoglobin less than optimum if it can be increased by additional dietary iron?' (Anon., 1967). 'Even if it does (increase), the haematological change may not be accompanied by increased well-being' (Leading Article, 1968). ' . . . whether "sub-optimal" blood indices have any significance to health and well-being are important questions indeed. Who is doing anything about it?' (Anon., 1968). As already stated, the orthodox view is that in all subjects, anaemic or non-anaemic, in whom a rise in haematological values is demonstrable following iron supplementation, a response denotes, ipso facto, previous deficiency. It is questionable, however, whether the implied almost world-wide state of deficiency can be established as such when measured against the specific criteria for a deficiency disease as laid down by Yudkin (1961). The protagonists of the orthodox view can establish their belief by the unequivocal demonstration that in a given community, subjects with higher than average haemoglobin values (or other indices of iron status), either occurring naturally or sustained by supplementary iron, have a detectably higher health status, demonstrable over the years, compared with those with lower haemoglobin levels, ranging down to, say, $10 \mathrm{~g} / 100 \mathrm{ml}$. The only alternative to the orthodox view is that iron can stimulate erythropoiesis in nonanaemic people. This view is not without adherents (Widdowson \& McCance, 1937; Hynes, Ishaq \& Verma, 1946; Dubach, Callender \& Moore, 1948; Baird \& Hytten, 1959; Witts, 1964; Hawkins, 1964; Paintin et al., 1966; Elwood, 1968). Thus, Paintin et al. (1966) maintain that 'iron in large quantities has a specifically stimulating effect on erythropoiesis'. Apart from the outright rejection of this possibility (Undritz, 1964; Pollycove, 1964), there has been no reasoned attempt to answer it. Most persons can gain weight with consummate ease, and can readily elevate levels of lipids and vitamins in their blood, but without these responses reflecting previous need. Why then is it so immutably certain that every elevation of haemoglobin level implies that the previous level was sub-optimal?

Clarification of the role of specific nutrients has occasioned enormous research. Iron will be no exception. No 'instant' answers to the crucial questions that have been raised are likely to be attained. What specific investigations are required? Depletion studies, more acute than those undertaken by Conrad \& Crosby (1962), will be essential. Simulated depletion studies will also be necessary. Repletion, including placebo studies, will need to be carried out in suitable groups. The repletion, and, in measure, depletion investigations must include population groups both sophisticated and primitive, with contrasting nutritional status. A second avenue of approach concerns the carrying out of appropriate epidemiological studies, as suggested by Elwood (1968), and mentioned earlier.

It is well to recognize that the present time is one of controversy and of re-thinking on the interpretation and significance of many diverse biological measurements and health parameters (Walker, 1967). Thus, regarding growth, Garrow (1967) asks: 'Is the normal growth curve for a North American child necessarily optimum? Are children who are smaller... necessarily malnourished?' Waterlow \& Bunje (1966) have stated: 'Do different levels of intakes (of nutrients) produce different physiological states even though theo subject may be at all times in balance?... This is as subject which is being hotly discussed at the presen time in relation to protein intake and requirements. Commenting on the high level of vitamin $\mathrm{C}$ intake recommended in U.S.A., a Leading Article (1964) in the Lancet wryly states: 'American nutritionists remain adamant that this intake benefits health, but their efforts to convince scientists in other countries of this have been totally unsuccessful.' As other examples: in a recent paper entitled 'The Normal Range-a Common Misuse', it is stated: "The conventional "normal range" is an unsatisfactory yardstick for decisions. ... In practice... the "normal range" provides information which is mostly irrelevant and is largely ignored by the experienced clinician' (Murphy \& Abbey, 1967). Mann (1964), with heavy sarcasm, asks: 'Do we wish to proceed on the belief that a deviation from the norm is all bad, life-shortening, and grounds for correction?'

This robust 'agonizing', to use a popular description, would have delighted the heart of Francis Galton who inveighed against the situation whereby beliefs 'when they are of long standing ... . become fixed rules of life and assume a prescriptive right not to be questioned' (Mann, 1964).

\section{References}

Anaemia in Africa: Conference (1962a) Lancet, ii, 265. 
Anaemia in Africa: Conference (1962b) East Afr. med. J. 39, 167.

Andelman, M.B. \& SeRed, B.R. (1966) Utilization of dietary iron by term infants. A study of 1048 infants from a low socio-economic population. Amer. J. Dis. Child. 111, 45.

ANON. (1967) Symptoms of iron deficiency anaemia. Nutr. Rev. 25, 86.

ANON. (1968) The prevalence of iron deficiency anaemia. Nutr. Rev. 26, 263.

BAIRD, D. \& HYTten, F.E. (1959) Anaemia in pregnancy. Lancet, i, 101.

Beutler, E. (1964) Tissue effects of iron deficiency. Iron Metabolism, p. 256. Springer-Verlag, Berlin.

Callender, S.T. (1964) Iron deficiency-discussion. Iron Metabolism, p. 278. Springer-Verlag, Berlin.

Cochrane, A.L. \& Elwood, P.C. (1968) Iron deficiency without anaemia. Lancet, $\mathbf{i}, 591$.

ConRad, M.E. \& Crosby, W.H. (1962) The natural history of iron deficiency induced by phlebotomy. Blood, 20, 173.

COUNCIL ON Foods AND Nutrition (1968) Iron deficiency in the United States. J. Amer. med. Ass. 203, 407.

Crosby, W.H. (1966) Iron metabolism. Disease-A-Month, 8, 3.

Davis, R.H., Jacobs, A. \& Rivlin, R. (1967) Dietary iron and haematological status in normal subjects. Brit. med. J. 3, 711 .

Department of Health and Social Security (1969) Recommended intakes of nutrients for the United Kingdom. Report of Public Health and Medical Subjects, No. 121. Her Majesty's Stationery Office, London.

DOMESTIC FoOD CONSUMPTION AND EXPENDITURE (1961) Ministry of Agriculture, Fisheries and Food (1963). Her Majesty's Stationery Office, London.

Dreyfus, B. (1964) Introduction to the general discussion. Iron Metabolism, p. 497. Springer-Verlag, Berlin.

Dubach, R., Callender, S.T.E. \& Moore, C.V. (1948) Studies in iron transportation and metabolism. VI. Absorption of radio-active iron in patients with fever and with anaemias of varied etiology. Blood, 3,526 .

EdITOR (1961) Prevalence of anaemia. Brit. med. J. 2, 1762.

EDITOR (1963) Pregnancy anaemia. Lancet, i, 607.

Elwood, P.C. (1968) Some epidemiological problems of iron deficiency anaemia. Proc. nutr. Soc. 27, 14.

Finch, C.A. (1965) Iron balance in man. Nutr. Rev. 23, 129.

Elwood, P.C., Waters, W.E., Greene, W.J.W., Sweetnam, P. \& Wood, M.M. (1969) Symptoms and the circulating haemoglobin level. J. chron. Dis. 21, 615.

FoY, H. \& Kondi, A. (1957) Anaemia of the tropics; relation to iron intake, absorption and losses during growth, pregnancy and lactation. J. trop. med. Hyg. 60, 105.

FrY, J. (1961) Clinical patterns and course of anaemias in general practice. Brit. med. J. 2, 1732.

GARROW, J.S. (1967) Growth of children after malnutrition. Lancet, i, 278.

HawkINs, W.W. (1964) Iron, copper and cobalt. Nutrition (Ed. by G.H. Beaton and E.W. McHenry), Vol. I, p. 309. Academic Press, London.

Hynes, M., IshaQ, M. \& Verma, O.P. (1946) The effect of different diets and of iron medication on the nutritional anaemia of Indian Army recruits. Ind. J. med. Res. 34, 273.

HytTen, F.E. \& Duncan, D.L. (1956) Iron deficiency anaemia in the pregnant woman and its relation to normal physiological changes. Nutr. Abstr. Rev. 26, 855.

KERR, D.N.S. \& DAVIDSON, S. (1958) The prophylaxis of iron deficiency anaemia in pregnancy. Lancet, ii, 483.
Kilpatrick, G.S. (1966) Pre-symptomatic diagnosis of anaemia. Proc. roy. Soc. Med. 59, 1220.

LEADING ARTICLE (1958) Anaemia in pregnancy. Lancet, ii, 1360.

Leading Article (1963) Pregnancy anaemia. Lancet i, 309.

Leading Article (1964) The American and his diet. Lancet, i, 1373.

LeADING ARTICLE (1968) Iron in flour. Brit. med. J. 4, 467.

Lillie, E.W., Gatenby, P.B.B. \& Moore, H.C. (1954) A survey of anaemia in 4314 cases of pregnancy. Irish J. med. Sci. 6, 304.

MACKAY, H.H.M. (1931) Nutritional anaemia in infancy. Spec. Rep. Ser. Med. Res. Coun., No. 157. Her Majesty's Stationery Office, London.

Magee, H.E. \& Milligan, E.H.M. (1951) Haemoglobin levels before and after labour. Brit. med. J. 2, 1307.

ManN, G.V. (1964) Concept of predisposition. Arch. Environ. Hlth, 8, 840.

Mitchell, R.G. (1966) Nutritional influences in early life. Proc. roy. Soc. Med. 59, 1073.

Moore, C.V. (1964) Iron nutrition. Iron Metabolism, p. 241. Springer-Verlag, Berlin.

MurPhy, E.A. \& ABBEY, H. (1967) The normal rangea common misuse. J. chron. Dis. $20,79$.

Osler, W. \& MaCrae, T. (1923) Principles and Practice of Medicine, 9th edn, p. 102. Appleton, London.

Paintin, D.B., Thomson, A.M. \& Hytten, F.E. (1966) Iron and haemoglobin level in pregnancy. J. Obstet. Gynaec. Brit. Cwlth, 73, 181.

Pollycove, M. (1964) Iron deficiency-discussion; and Therapeutics-discussion. Iron Metabolism, pp. 276 and 445. Springer-Verlag, Berlin.

Sturgeon, P. (1959) Studies of iron requirements in infants. III. Influence of supplemented iron during normal pregnancy on mother and infant. Brit. J. Haemat. 5, 45.

Thomson, A.M., Hytten, F.E. \& Paintin, D.B. (1967) Folate supplements in pregnancy. Brit. med.J. 1, 565.

Trowell, H.C. (1960) Non-Infective Disease in Africa, p. 384. Edward Arnold, London.

UNDRITZ, E. (1964) Oral treatment of iron deficiency. Iron Metabolism, p. 406. Springer-Verlag, Berlin.

Walker, A.R.P. (1963) Problems in nutritional supplementation and enrichment. Amer. J. clin. Nutr. 12, 157.

WALKER, A.R.P. (1967) Interpretation of data on one ethnic or regional group may not be equally applicable to other groups. Amer. J. clin. Nutr. 20, 1025.

WATERlow, J.C. \& BUNJE, H.W. (1966) Mountain sickness. Lancet, ii, 1132.

WHO EXPERT COMmITTEE RePORT (1959) Iron deficiency anaemia. Wld Hlth Org. Tech. Rep. Ser., No. 182, Geneva.

WHO EXPERT COMmittee RePORT (1965) Nutrition in pregnancy and lactation. Wld Hlth Org. Tech. Rep. Ser., No. 302, Geneva.

WHO REPORT of a ScIENTIFIC Group (1968) Nutritional anaemias. Wld Hlth Org. Tech. Rep. Ser., No. 405, Geneva.

Widdowson, E.M. \& McCANCE, R.A. (1936) Iron in human nutrition. J. Hyg., Camb. 36, 13.

WitTs, L.J. (1964) Therapeutics-discussion; and Summing up. Iron Metabolism, pp. 443 and 612. Springer-Verlag, Berlin.

Wood, M.M. \& Elwood, P.C. (1966) Symptoms of iron deficiency in anaemia. A community survey. Brit. $J$. prev. Soc. Med. 20, 117.

Yudkin, J. (1961) Fatty acids and coronary disease. Practitioner, 187, 150. 